\title{
Docosahexaenoic acid inhibits zymogen activation by suppressing vacuolar ATPase activation in cerulein-stimulated pancreatic acinar cells
}

Yeeun Park, Leeyeon Ku, Joo Weon Lim and Hyeyoung Kim

\begin{abstract}
Background: The premature activation of digestive enzyme zymogens within pancreatic acinar cells is an important early feature of acute pancreatitis. Supraphysiological concentrations of cholecystokinin (CCK) cause intrapancreatic zymogen activation and acute pancreatitis. Stimulation of vacuolar ATPase (vATPase) activity is required for zymogen activation in pancreatic acinar cells. Parkin, a multiprotein E3 ubiquitin ligase complex, promotes vATPase ubiquitination and degradation, which inhibits VATPase activity. Docosahexaenoic acid (DHA), an omega-3 fatty acid, exerts anti-inflammatory effects. It is reported to bind to G-protein coupled receptor 120 (GPR120) and GPR40. DHA induces the degradation of certain proteins by activating ubiquitin-proteasome system in various cells. This study aimed to investigate whether DHA induces Parkin and inhibits VATPase activity, resulting in zymogen inactivation in pancreatic acinar AR42J cells stimulated with cerulein, a CCK analog.

Results: Cerulein induced the translocation of the cytosolic V1 domain (E subunit) of VATPase to the membrane, which indicated VATPase activation, and zymogen activation in AR42J cells. DHA suppressed the association of the vATPase with membranes, and zymogen activation (increased trypsin activity and amylase release) induced by cerulein. Pretreatment with a GPR120 antagonist AH-7614, a GPR40 antagonist DC260126, or an ubiquitination inhibitor PYR-41 reduced the effect of DHA on cerulein-induced zymogen activation. Treatment with PYR-41 reversed the DHA-induced decrease in VATPase activation in cerulein-treated cells. Furthermore, DHA increased the level of Parkin in membranes of cerulein-treated cells.
\end{abstract}

Conclusions: DHA upregulates Parkin which inhibits vATPase-mediated zymogen activation, via GPR120 and GPR40, in cerulein-stimulated pancreatic acinar cells.

Keywords: Cerulein, Docosahexaenoic acid (DHA), Pancreatic acinar cells, Parkin, Vacuolar ATPase (vATPase), Zymogen

\section{Background}

The pancreatic acinar cell, which comprises over $90 \%$ of the exocrine pancreas, synthesizes and secretes the enzymes required to digest nutrients. Many of these digestive enzymes are stored in acinar cells as inactive zymogens that become activated only after reaching the

\section{* Correspondence: kim626@yonsei.ac.kr}

Department of Food and Nutrition, Brain Korea 21 PLUS Project, College of Human Ecology, Yonsei University, Seoul 03722, Korea small intestine. Premature activation of these zymogens within acinar cells appears to have a critical role in initiating acute pancreatitis [1], which can result in autodigestion of the pancreas and multiple organ dysfunction. It is also associated with increased cytokine production and release, ultimately leading to deleterious local and systemic effects [2-4]. Similar symptoms are observed in cerulein pancreatitis, one of the best characterized and widely used experimental animal models of pancreatitis.

(c) The Author(s). 2020 Open Access This article is licensed under a Creative Commons Attribution 4.0 International License, which permits use, sharing, adaptation, distribution and reproduction in any medium or format, as long as you give

appropriate credit to the original author(s) and the source, provide a link to the Creative Commons licence, and indicate if changes were made. The images or other third party material in this article are included in the article's Creative Commons licence, unless indicated otherwise in a credit line to the material. If material is not included in the article's Creative Commons licence and your intended use is not permitted by statutory regulation or exceeds the permitted use, you will need to obtain permission directly from the copyright holder. To view a copy of this licence, visit http://creativecommons.org/licenses/by/4.0/. 
Supramaximal doses of cerulein, a cholecystokinin (CCK) analog, result in experimental pancreatitis $[5,6]$. Doses of cerulein beyond those that cause the maximum pancreatic secretion of amylase and lipase $[7,8]$ result in pancreatitis, which is characterized by a dysregulation of the production and secretion of digestive enzymes. In particular, pancreatitis is characterized by abnormal pancreatic secretion and an elevation in the serum levels of digestive enzymes, cytoplasmic vacuolization, and the death of acinar cells, edema formation, and an infiltration of inflammatory cells into the pancreas $[9,10]$. The mortality rate in patients with acute pancreatitis has decreased over the last decade due to improvements in critical care. However, the worldwide incidence of acute pancreatitis remains high [11].

Although the mechanisms involved in the pathogenesis of pancreatitis are not completely elucidated, the premature activation of zymogens in pancreatic acinar cells is regarded as a major pathogenic factor in acute pancreatitis [12, 13]. Induction of experimental pancreatitis in rat pancreatic acini with supraphysiological doses of cerulein causes an increase in intracellular zymogen activation [14].

Vacuolar ATPase (vATPase) is an ATP-dependent proton pump found within the membranes of many organelles [15]. vATPase is composed of an integral membrane domain (V0) and a peripheral complex (V1). The V1 domain must be transported to the membrane and assemble with the V0 domain to activate vATPase [16]. Cerulein is known to induce the activation of vATPase in pancreatic acini [17]. The V1 domain of vATPase consists of eight subunits, A-H. Translocation of the $\mathrm{E}$ subunit to the membrane activates vATPase in pancreatic acinar cells [17] and pancreatic cancer cells [18]. Therefore, translocation of the E subunit from the cytosol to the membrane was used an index of vATPase activation in ceruleintreated pancreatic acinar cells in the present study.

It was recently reported that vATPase activity is required for zymogen activation in pancreatic acinar cells [19]. Considerable evidence indicates that cerulein stimulates zymogen activation and that specific inhibitors of vATPase, such as bafilomycin A1 and concanamycin A, inhibit ceruleininduced zymogen activation. Martinez et al. [20] reported that vATPase could be ubiquitinated by Parkin. These data suggest that Parkin may protect the cells against premature zymogen activation by reducing vATPase activation through the induction of proteasome-mediated degradation.

Docosahexaenoic acid (DHA), an omega-3 polyunsaturated fatty acid (PUFA), is the longest and the most unsaturated fatty acid, with 22 carbons and 6 double bonds (C22:6n-3). DHA has been known to exert antiinflammatory and anti-oxidant effects, resulting in the prevention of various diseases, including cardiovascular diseases and autoimmune diseases [21]. DHA is known to act as endogenous ligand of G-protein coupled receptor 120 (GPR120) [22] and GPR40 (free fatty acid receptor 1) [23]. DHA exerts anti-inflammatory effects via the GPR-120-mediated pathway in various cell lines [24]. In animal experiment, DHA inhibited a complete Freund's adjuvant (CFA)-induced inflammatory chronic pain via GPR40 signaling pathway [25]. Moreover, recent studies indicate that DHA can induce the degradation of some proteins by activating the ubiquitin-proteasome system in cells $[26,27]$. Therefore, we hypothesize that DHA may prevent acute pancreatitis by inducing Parkin-mediated degradation of vATPase and thus, reducing zymogen activation in pancreatic acinar cells.

The aim of this study was to investigate whether DHA inhibits zymogen activation by upregulating Parkin and inhibiting vATPase activation in cerulein-stimulated pancreatic acinar AR42J cells.

\section{Results}

Cerulein activated the E subunit of vATPase in AR42J cells To investigate whether cerulein induces vATPase activation in AR42J cells, the levels of the vATPase V1 domain (E subunit) in the cytosol and membrane fractions were determined using an antibody against the vATPase E subunit. Cerulein did not change vATPase E subunit levels in total cell extracts (Fig. 1a). However, as shown in Fig. 1b, cerulein increased the levels of the vATPase E subunit in the membrane fraction but decreased its levels in the cytosolic fraction of AR42J cells. Levels of the cytosolic marker, aldolase $\mathrm{A}$, and the membrane marker, $\mathrm{Na}^{+} / \mathrm{K}^{+}$-ATPase, were not changed by cerulein. These results indicate that cerulein induces the translocation of the V1 domain (E subunit)

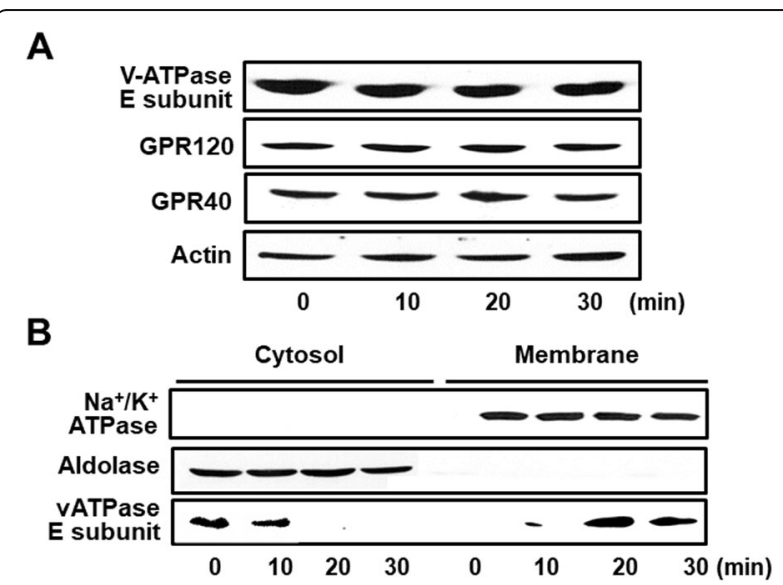

Fig. 1 Cerulein-induced translocation of the $E$ subunit of vATPase to the membrane. Cells were stimulated with cerulein $\left(10^{-8} \mathrm{M}\right)$ for the indicated time periods. a Levels of GPR120, GPR40, and vATPase E subunit in total cell extracts were determined by western blot analysis. Actin was used as a loading control. $\mathbf{b}$ Levels of vATPase $\mathrm{E}$ subunit in cytosolic and membrane fractions were determined by western blot analysis. Aldolase $\mathrm{A}$ and $\mathrm{Na}^{+} / \mathrm{K}^{+}$-ATPase were used as markers of cytosolic and membrane fractions, respectively 
to the membrane in AR42J cells. In addition, GPR120, an omega-3 fatty acid receptor, and GPR40, a free fatty acid receptor 1 , were not affected by cerulein treatment (Fig. 1a).

\section{DHA inhibited the cerulein-induced activation of vATPase} in AR42J cells

To determine the effect of DHA on cerulein-induced translocation of the vATPase E subunit to the membrane, the levels of the vATPase E subunit in cytosolic and membrane fractions were determined by western blot analysis. Pretreatment with DHA decreased the vATPase E subunit levels in total cell extracts (Fig. 2a). As shown in Fig. 2b, the cerulein-induced increase in vATPase $E$ subunit levels in membrane fractions was suppressed by DHA. These results suggest that DHA decreases the expression of the vATPase E subunit and the activation of vATPase in cerulein-treated AR42J cells. GPR120 and GPR40 levels were not affected by cerulein treatment alone or following DHA pretreatment.

\section{DHA inhibited the cerulein-induced activation of zymogens in AR42J cells}

As shown in Fig. 3, cerulein stimulation increased trypsin activity and amylase release, which are markers of zymogen activation in pancreatic acinar cells. DHA decreased trypsin activity and amylase release in ceruleinstimulated cells in a dose-dependent manner (Fig. 3a, b).

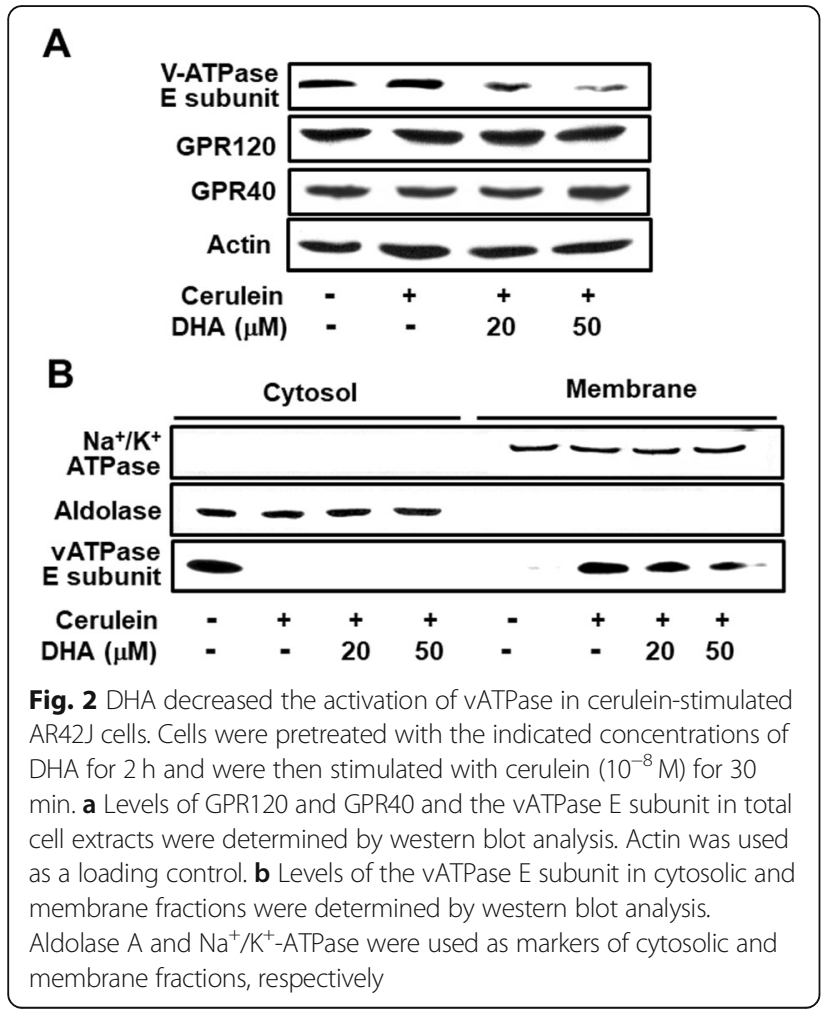

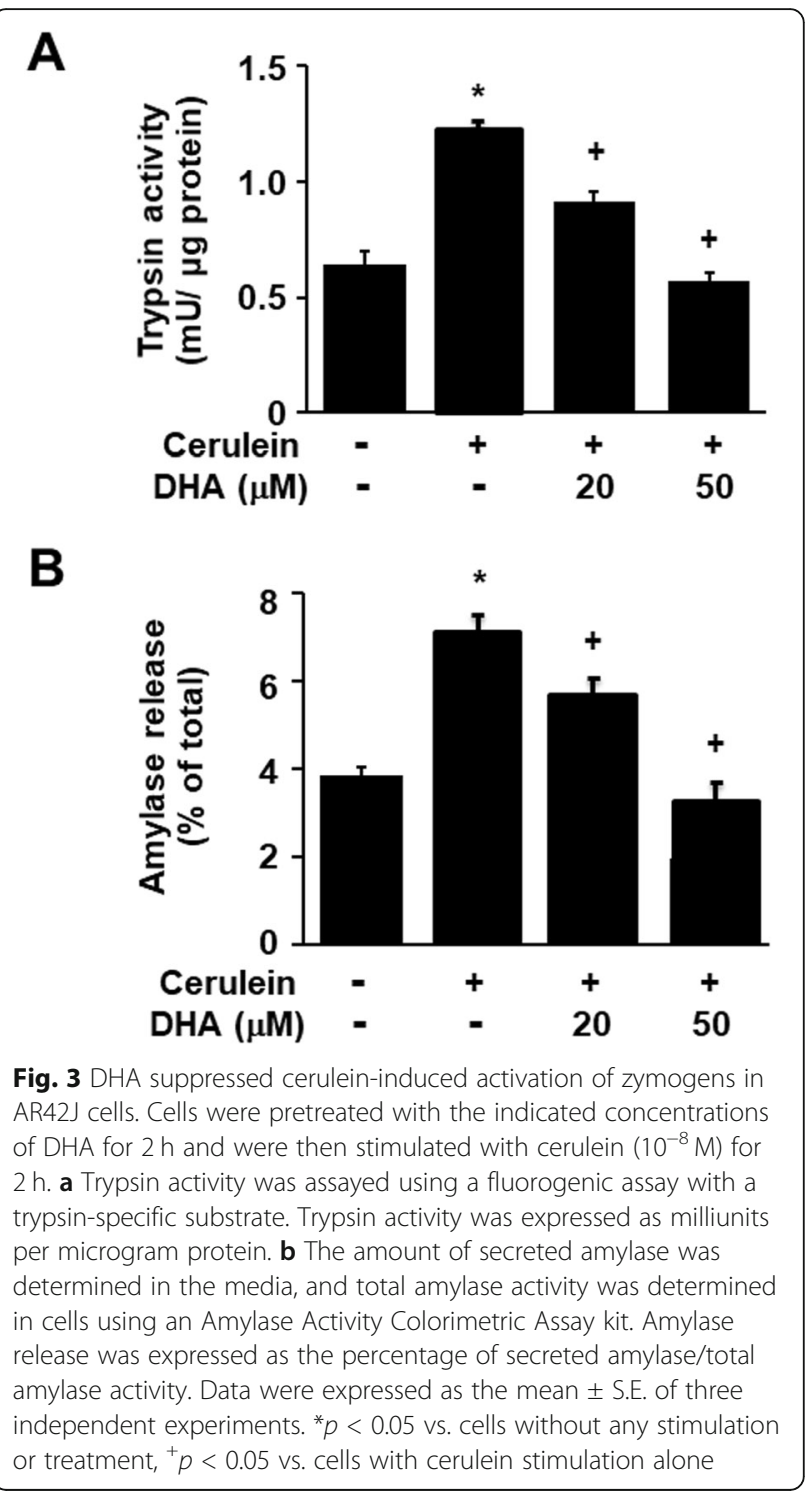

GPR120 and GPR40 antagonist suppressed the inhibitory effect of DHA on zymogen activation in ceruleinstimulated AR42J cells

To elucidate the mechanism underlying the inhibitory effect of DHA on cerulein-induced zymogen activation via the GPR120 and GPR40 signaling pathway, we investigated whether a GPR120 antagonist AH-7614 and a GPR40 antagonist DC260126 could suppress this inhibitory effect of DHA. As shown in Fig. 4, cerulein stimulation increased zymogen activation, and this was inhibited by DHA. However, AH-7614 suppressed the inhibitory effect of DHA on cerulein-induced zymogen activation. In addition, the inhibitory effect of DHA on cerulein-induced zymogen activation was also suppressed by DC260126 (Fig. 5). These results demonstrate that DHA inhibits zymogen activation via GPR120 or GPR40-mediated pathway in cerulein-stimulated AR42J cells. 


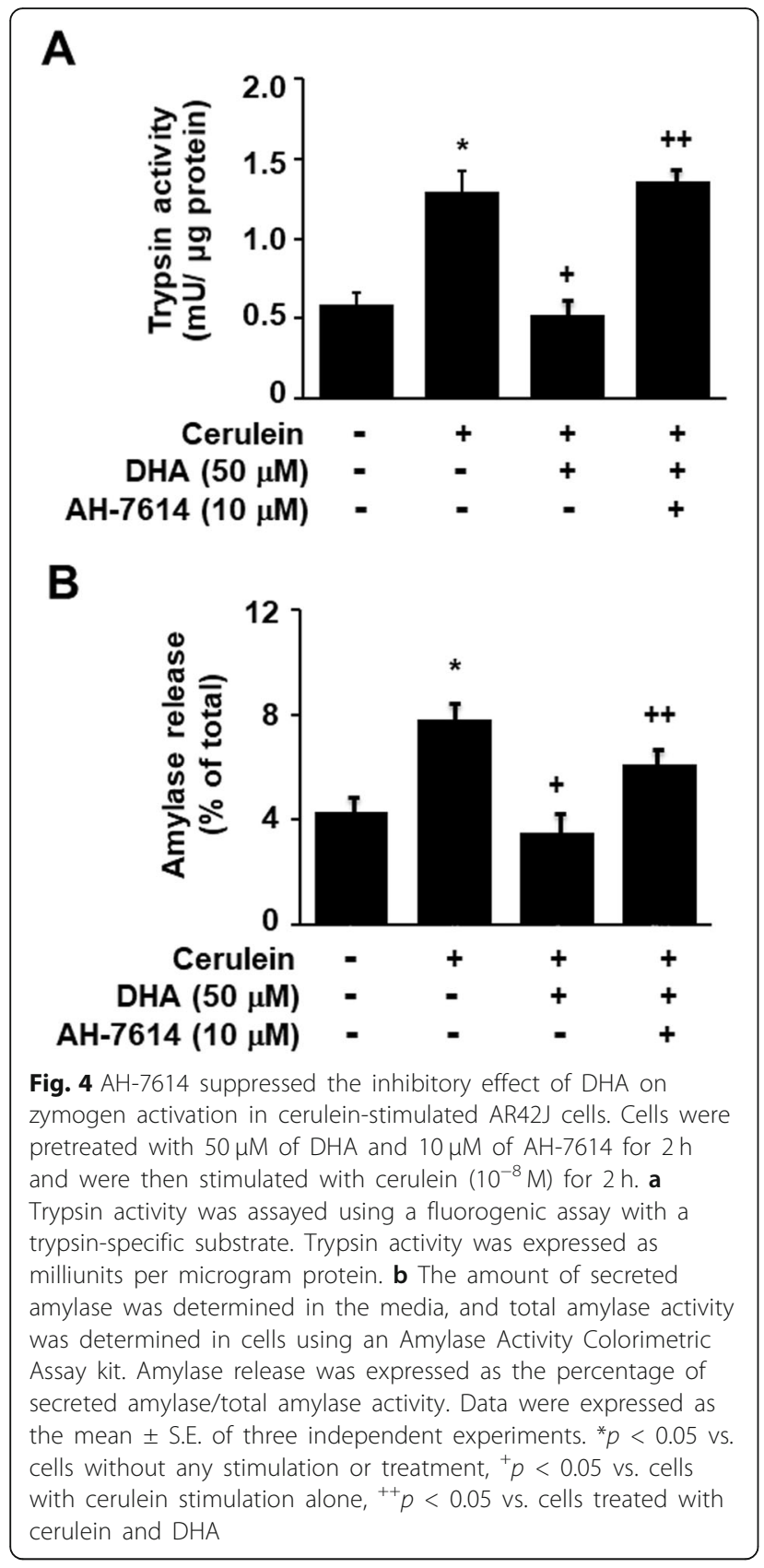

DHA decreased vATPase in membrane fractions by ubiquitination and degradation of vATPase

To investigate whether DHA induced the ubiquitination of vATPase, cellular proteins were subjected to immunoprecipitation with an anti-ubiquitin antibody, followed by western blotting detecting of the $E$ subunit of vATPase (Fig. 6a). DHA increased the interaction of the vATPase $E$ subunit with ubiquitin. Amount of input vATPase E subunit was determined by western blotting at the same time as the control. To determine whether DHA induced the ubiquitination and degradation of vATPase, we investigated the

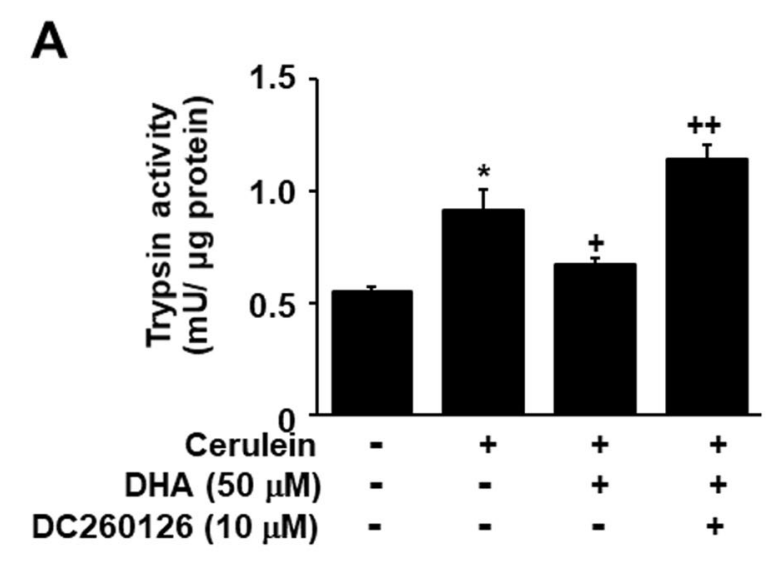

B

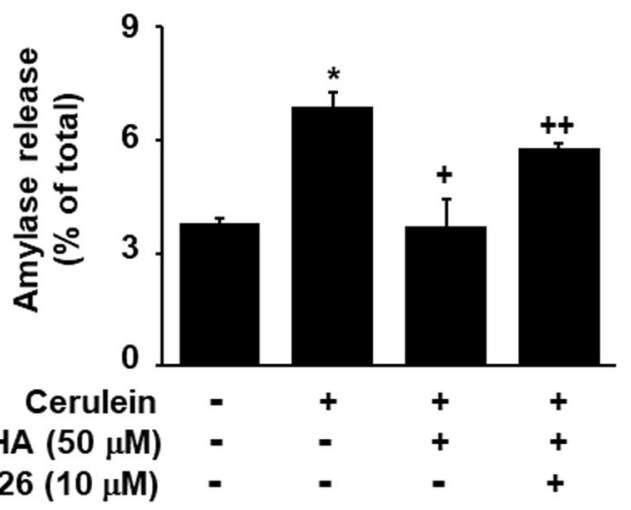

Fig. 5 DC260126 reversed the inhibitory effect of DHA on cerulein -induced activation of zymogen in AR42J cells. Cells were pretreated with $50 \mu \mathrm{M}$ of DHA and $10 \mu \mathrm{M}$ of DC260126 for $2 \mathrm{~h}$ and were then stimulated with cerulein $\left(10^{-8} \mathrm{M}\right)$ for $2 \mathrm{~h}$. a Trypsin activity was assayed using a fluorogenic assay with a trypsin-specific substrate. Trypsin activity was expressed as milliunits per microgram protein. $\mathbf{b}$ The amount of secreted amylase was determined in the media, and total amylase activity was determined in cells using an Amylase Activity Colorimetric Assay kit. Amylase release was expressed as the percentage of secreted amylase/total amylase activity. Data were expressed as the mean \pm S.E. of three independent experiments. ${ }^{*} p<0.05$ vs. cells without any stimulation or treatment, ${ }^{+} p<0.05$ vs. cells with cerulein stimulation alone, ${ }^{++} p<0.05$ vs. cells treated with cerulein and DHA effect of the ubiquitination inhibitor, PYR-41, on the membrane levels of the vATPase E subunit. As shown in Fig. 6b, PYR-41 suppressed the DHA-induced degradation of the vATPase $E$ subunit. Furthermore, the DHA-induced decrease in membrane expression of the vATPase E subunit was suppressed by PYR-41 in cerulein-stimulated AR42J cells (Fig. 6c). These data indicate that DHA may induce the ubiquitination and degradation of membrane vATPase, resulting in the degradation of vATPase. The cytosolic marker, aldolase $A$, and the membrane marker, $\mathrm{Na}^{+} / \mathrm{K}^{+}$-ATPase, were not affected by any of these treatments. 


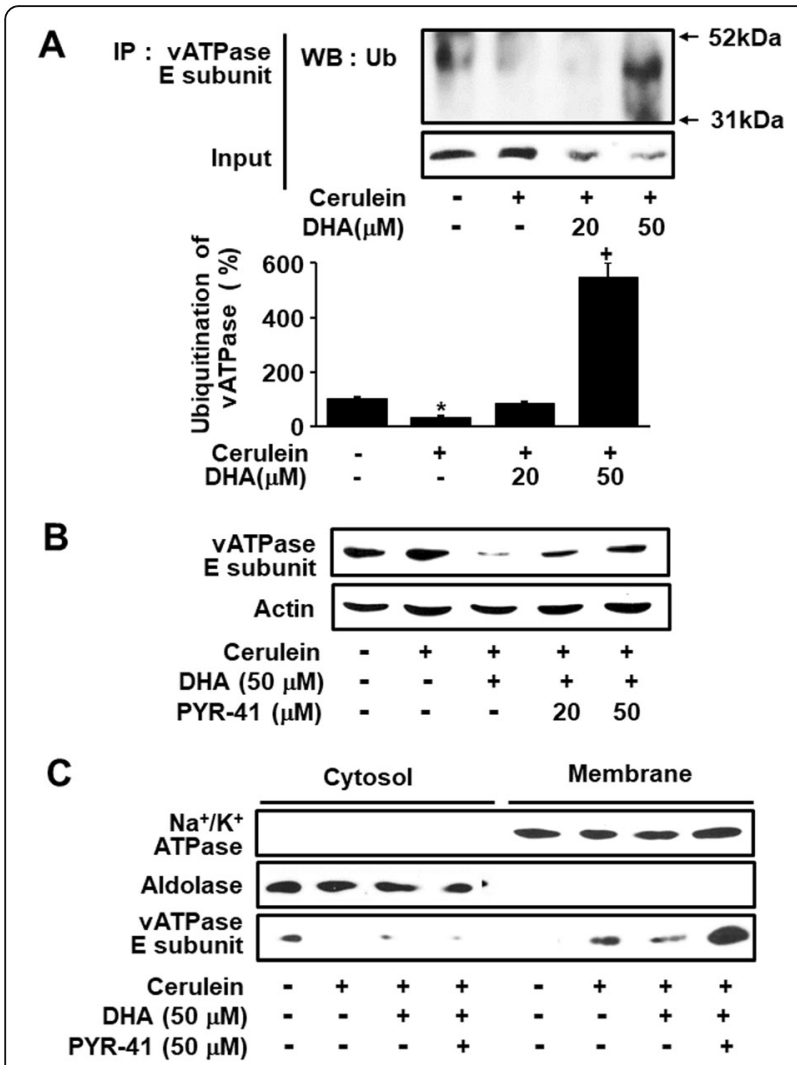

Fig. $6 \mathrm{DHA}$ decreased the levels of vATPase via ubiquitination in AR42J cells. a Cells were pretreated with the indicated concentrations of DHA for $2 \mathrm{~h}$ and were then stimulated with cerulein $\left(10^{-8} \mathrm{M}\right)$ for $30 \mathrm{~min}$. Total cell extracts were prepared and subjected to immunoprecipitation (IP) analysis with anti-vATPase E subunit antibody, followed by western blotting (WB) with an anti-ubiquitin (Ub) antibody. Input was used as a control for protein expression determined by western blotting. The upper lane shows total cell extracts subjected to IP with an anti-vATPase E subunit antibody, followed by WB with an anti-ubiquitin antibody. The lower lane shows the amount of input VATPase E subunit determined with western blot analysis (upper panel). The level of the band densities corresponding to ubiquitinated VATPase $\mathrm{E}$ subunit to that of its input control was calculated. The band density level of "None" was set as 100\%. Values are expressed as the mean \pm S.E. of three/each group. ${ }^{*} p<0.05$ vs. cells without any stimulation or treatment, ${ }^{+} p<0.05$ vs. cells with cerulein stimulation alone (lower panel). b Cells were pretreated with DHA $(50 \mu \mathrm{M})$ and the ubiquitination inhibitor, PYR-41 (20 or $50 \mu \mathrm{M})$, for $2 \mathrm{~h}$ and were then stimulated with cerulein $\left(10^{-8} \mathrm{M}\right)$ for $2 \mathrm{~h}$. Protein levels of the VATPase $\mathrm{E}$ subunit were determined by western blotting. Actin was used as a loading control. c Levels of the vATPase E subunit in cytosolic and membrane fractions were determined by western blot analysis. Aldolase A and $\mathrm{Na}^{+} / \mathrm{K}^{+}$-ATPase were used as markers of cytosolic and membrane fractions, respectively

The ubiquitination inhibitor, PYR-41, suppressed the inhibitory effect of DHA on zymogen activation in cerulein-stimulated AR42J cells

To confirm the effect of DHA on the ubiquitination of vATPase, we investigated whether the ubiquitination inhibitor, PYR-41, could suppress the inhibitory effect of
DHA on cerulein-induced zymogen activation in AR42J cells. As shown in Fig. 7, DHA inhibited ceruleininduced zymogen activation. However, PYR-41 suppressed the inhibitory effect of DHA on zymogen activation in cerulein-stimulated AR42J cells. These results suggest that DHA induces the ubiquitination and degradation of vATPase and suppresses zymogen activation in cerulein-stimulated AR42J cells.

DHA increased the protein levels of Parkin in AR42J cells Since vATPase is ubiquitinated by Parkin, which is a component of the multiprotein E3 ubiquitin ligase

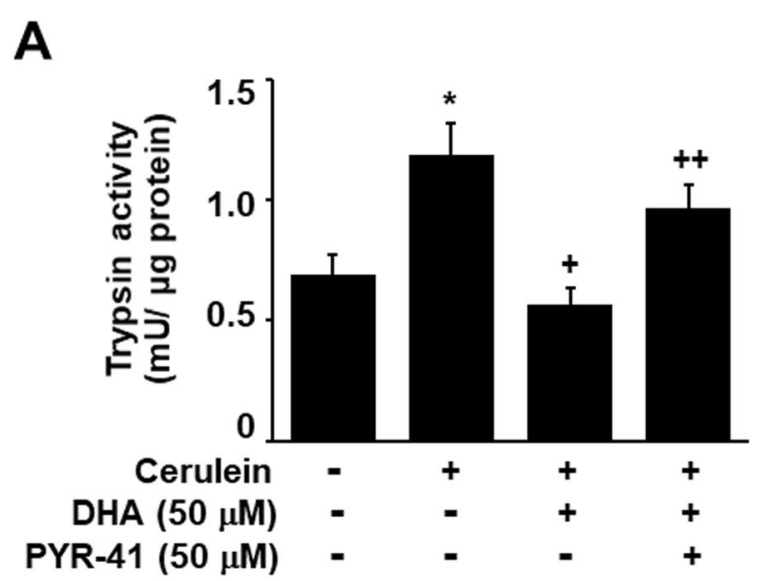

B

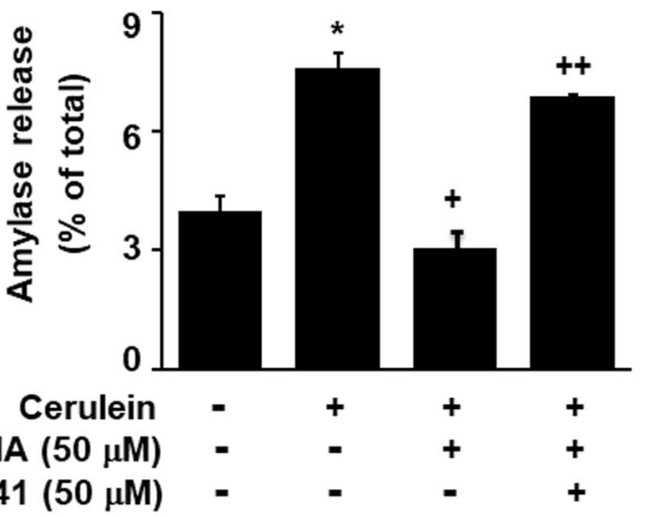

Fig. 7 PYR-41 suppressed the inhibitory effect of DHA on zymogen activation in cerulein-stimulated AR42J cells. Cells were pretreated with DHA $(50 \mu \mathrm{M})$ and/or PYR-41 $(50 \mu \mathrm{M})$ for $2 \mathrm{~h}$ and were then stimulated with cerulein $\left(10^{-8} \mathrm{M}\right)$ for $2 \mathrm{~h}$. a Trypsin activity was assayed using a fluorogenic assay with a trypsin-specific substrate. Trypsin activity was expressed as milliunits per microgram protein. $\mathbf{b}$ The amount of secreted amylase was determined in the media, and total amylase activity was determined in cells using an Amylase Activity Colorimetric Assay kit. Amylase release was expressed as the percentage of secreted amylase/total amylase activity. Data were expressed as the mean \pm S.E. of three independent experiments. ${ }^{*} p$ $<0.05$ vs. cells without any stimulation or treatment, ${ }^{+} p<0.05$ vs. cells with cerulein stimulation alone, ${ }^{++} p<0.05$ vs. cells treated with cerulein and DHA 
complex, we performed western blotting to investigate whether DHA increases the expression of Parkin. As shown in Fig. 8a, DHA increased the levels of Parkin in cerulein-stimulated AR42J cells. Furthermore, Parkin levels in membrane fractions were increased by DHA in cerulein-stimulated cells (Fig. 8b), indicating that DHAinduced Parkin is localized to the membrane. These results demonstrate that the ubiquitination and degradation of membrane vATPase may have been mediated by Parkin, which is upregulated by DHA in ceruleinstimulated cells.

\section{Discussion}

The main role of the exocrine pancreas is to synthesize and secrete large amounts of digestive enzymes as inactive precursor zymogens. In acinar cells, these enzymes exist in inactive states within zymogen granules due to protease inhibitors, resulting in the inhibition of premature and intracellular activation of these digestive enzymes [27, 28]. However, when physiological conditions worsen, pancreatic autodigestion is initiated by premature zymogen activation, and acute pancreatitis can develop [29]. Therefore, premature zymogen activation is a key mediator in pancreatic inflammation.

DHA has been reported to show greater anti-oxidant and anti-inflammatory activities than other omega-3 PUFAs in renal epithelial cells and macrophages [30]. However, the molecular mechanisms underlying the anti-inflammatory effects of DHA in acute pancreatitis have not been well established. Lei et al. [31] assessed whether treatment with omega-3 PUFAs provide

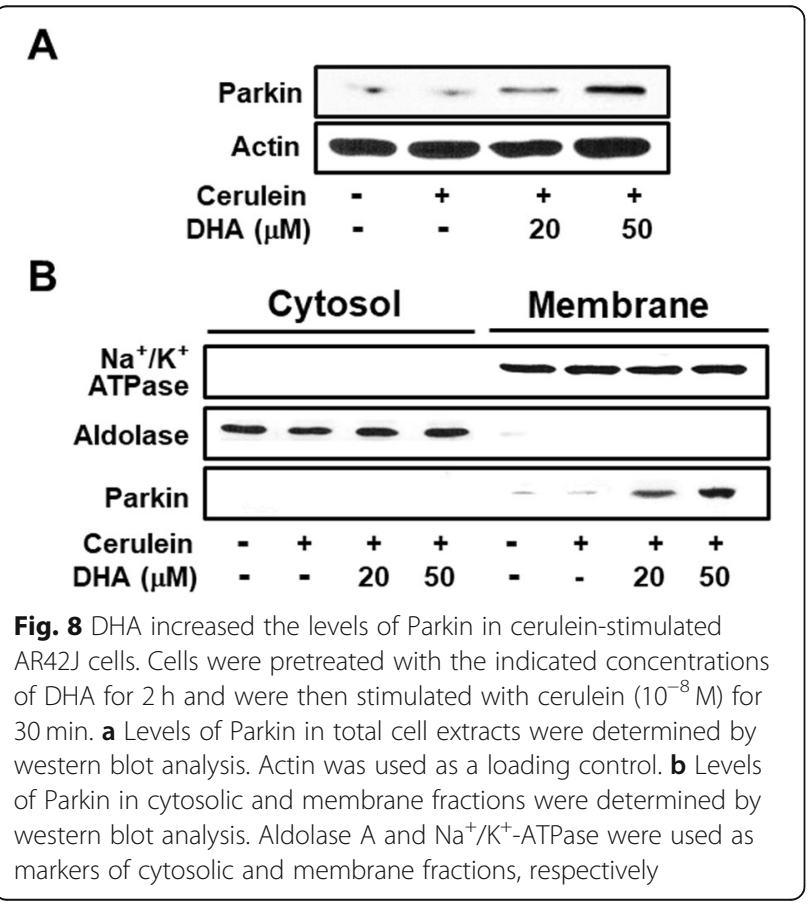

benefits to patients with acute pancreatitis based on literature database. They found that omega-3 PUFAs treatment resulted in a significantly reduced risk of mortality, infectious complications, and length of hospital stay. Previously, we reported that pretreatment with DHA reduced the cerulein-induced activation of nuclear factor kappa-light-chain-enhancer of activated B cells (NF-kB), protein kinase $C \delta$, and interleukin (IL)- 6 in pancreatic tissues of rats [32]. DHA suppressed pancreatic edema and decreased lipid peroxide levels, myeloperoxidase activity, and inflammatory cell infiltration into the pancreatic tissues of cerulein-treated rats.

We also reported that DHA suppressed the expression of inflammatory cytokines (IL-1 $\beta$, IL-6) and inhibited the activation of transcription factor activator protein-1 in cerulein-stimulated pancreatic acinar cells [33]. These results suggest that DHA may be beneficial for preventing oxidative stress-induced pancreatic inflammation by inhibiting inflammatory cytokine expression in pancreatic acinar cells. Moreover, we recently showed that DHA induces peroxisome proliferator-activated receptor $\gamma$ (PPAR $\gamma$ ) activation and catalase expression, which inhibits ROS-mediated activation of Janus kinase 2 (JAK2)/signal transducer and activator of transcription 3 (STAT3) and IL-6 expression in cerulein-stimulated pancreatic acinar cells [34]. However, there has been no report regarding the effects of DHA on zymogen activation in the pathogenesis of acute pancreatitis. In the present study, we found that DHA decreased trypsin activity and amylase release in cerulein-stimulated AR42J cells. Moreover, the present results showed that DHA suppresses zymogen activation via GPR120- and GPR40mediated pathway in AR42J cells.

Regarding zymogen activation in acute pancreatic inflammation, it has been reported that vATPase plays a central role in activating premature zymogens [35, 36]. Since vATPase acidifies the intracellular compartment, it is a candidate zymogen activator in pancreatic acini. Thus, we investigated whether DHA affects vATPase activity to inhibit zymogen activation in pancreatic acinar cells stimulated with cerulein. We found that cerulein induced the translocation of the vATPase V1 domain (E subunit) to membranes, which indicated vATPase activation. Furthermore, DHA decreased the levels of subunit $E$ of the V1 domain in total cell extracts and in membrane fractions.

As previously mentioned, DHA induces the degradation of certain proteins by activating the ubiquitinproteasome system $[25,26]$. In the present study, DHA increased the interaction of vATPase with ubiquitin in cerulein-stimulated cells. The DHA-induced decrease in vATPase (subunit E) levels was suppressed by a specific ubiquitin E1 inhibitor, PYR-41, in cerulein-stimulated cells. In addition, PYR-41 suppressed the inhibitory 
effect of DHA on cerulein-induced zymogen activation in pancreatic acinar cells. These results strongly suggest that DHA inhibits zymogen activation by inducing the ubiquitination of vATPase in cerulein-stimulated AR42J cells.

An interesting finding in the present study was the mechanism employed by DHA to induce the ubiquitination of vATPase. In recent years, Parkin has attained much attention in Parkinson's disease research. Several studies have demonstrated that Parkin, which is an E3 ubiquitin ligase, leads to the ubiquitination of multiple proteins $[37,38]$. Thus, we investigated whether DHA induces Parkin to decrease vATPase in AR42J cells stimulated with cerulein. Indeed, DHA was found to increase Parkin levels in the membrane fractions of ceruleinstimulated AR42J cells, suggesting that DHA may have induced the ubiquitination of membrane vATPase by upregulating Parkin in cerulein-stimulated cells.

Ubiquitin ligases have been largely thought to be constitutively active. Parkin is also known to be constitutively active due to its autoubiquitination [39, 40]. Therefore, ubiquitination of vATPase may occur in untreated cells, leading to its degradation. Piplani et al. [41] demonstrated that cerulein treatment reduces Parkin expression and increases the translocation of Parkin to mitochondria in pancreas. They demonstrated that cerulein decreases the effect of Parkin on ubiquitination of vATPase in membrane. In the present study, as shown in upper panel of Fig. 6a, untreated cells showed ubiquitination of vATPase while cerulein-treated cells reduced the interaction of the vATPase E subunit with ubiquitin. However, treatment of DHA (at $50 \mu \mathrm{M}$ ) in the presence of cerulein significantly increased the interaction of the vATPase E subunit with ubiquitin.

As shown in lower panel of Fig. 6a, we compared the level of the band density corresponding to ubiquitinated vATPase E subunit to that of its input control. The band density level of "None" was set as $100 \%$. Cerulein reduced ubiquitination of vATPase in AR42J cells. Treatment of DHA in the presence of cerulein increased ubiquitinated vATPase E subunit, which may be caused by upregulation of Parkin (as shown in Fig. 8) in AR42J cells.

Several studies reported that the cerulein significantly induces zymogen activation after 1 or $2 \mathrm{~h}$ in AR42J cells and isolated pancreatic acinar cells [42, 43]. Therefore, 2-h time point was used for determination of zymogen activation (trypsin activity, amylase release) in the present study. Further study should be performed whether cerulein treated with or without DHA affects expression of Parkin and activation of vATPase at 2-h culture.

In addition, Le Petit-Thévenin et al. [44] reported that treatment of DHA (50 and $100 \mu \mathrm{M}$ ) alone for 3 days did not significantly affect amylase release in AR42J cells. It is necessary to determine whether DHA alone changes trypsin activity and amylase release in AR42J cells for the future study.

A selective GPR120 antagonist AH-7614 and GPR antagonist DC 260126 suppressed the DHA-induced decrease in trypsin activity and amylase release in ceruleinstimulated cells. These results demonstrate that DHA inhibits zymogene activation, via GPR120 and GPR40, in pancreatic acinar cells stimulated with cerulein. Taken together, DHA upregulates Parkin which reduces vATPase-mediated zymogen activation, via GPR120 and GPR40, in cerulein-stimulated pancreatic acinar cells.

Ubiquitination is known to be constitutively active. Several studies report that PYR-41 alone treatment inhibited constitutive ubiquitination and degradation of proteins such as p53 and I $\mathrm{KB}$ in several cell lines [45, 46]. Therefore, treatment of PYR-41 alone may increase expression of membrane vATPase by inhibiting ubiquitination in cells. Moreover, there is no report about the effect of DC260126 on zymogen activation in pancreatic acinar cells. Therefore, further study should be performed to investigate whether treatment of PYR-41 alone or DC260126 alone affects activation of vATPase and zymogen in pancreatic acinar cells.

The limitation of the present study is that we only used one cell line in the present study; more cell lines and primary cells should be used to validate the present results in the future studies. In addition, to investigate the inhibitory effect and mechanism of DHA on cerulein-induced zymogen activation, further studies should be performed using in vivo experimental models.

\section{Conclusions}

Cerulein induces the translocation of the vATPase V1 domain (E subunit) to membranes, which may assemble with the V0 domain to activate vATPase in pancreatic acinar cells. vATP activation induces zymogen activation in cerulein-stimulated pancreatic acinar cells. DHA may bind to GPR 120 and GPR 40 and increases the level of Parkin which may induce the ubiquitination and degradation of membrane vATPase in cerulein-stimulated pancreatic acinar cells. Thus, DHA suppresses vATPasemediated zymogen activation that leads to decreasing trypsin activity and amylase release induced by cerulein in pancreatic acinar cells. As illustrated in Fig. 9, DHA inhibits zymogen activation by upregulating Parkin and suppressing vATPase, via GPR120 and GPR40, in cerulein-stimulated pancreatic acinar cells.

\section{Methods}

Reagents

DHA, a GPR120 antagonist AH-7614, an ubiquitination inhibitor PYR-41, and cerulein were purchased from 


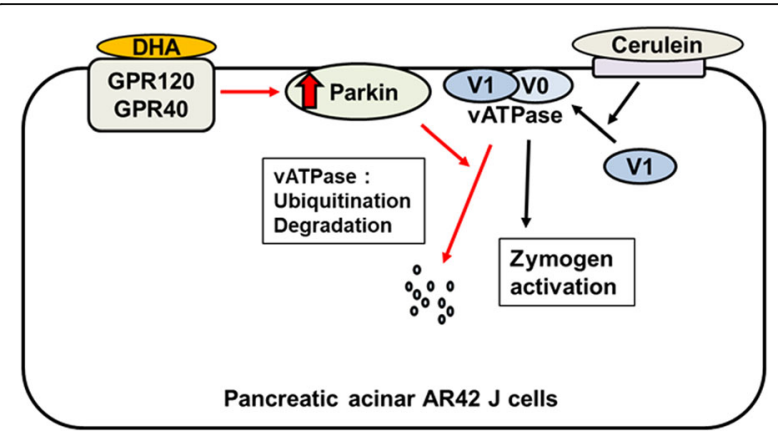

Fig. 9 Schematic pathways for inhibitory effect of DHA on ceruleininduced activation of zymogen in AR42J cells. Cerulein induces the translocation of the cytosolic V1 domain of VATPase to the membrane, which may assemble with the $V 0$ domain to activate vATPase in pancreatic acinar cells. vATPase activation may result in zymogen activation in pancreatic acinar cells. DHA binds to GPR120 and GPR40 which increases the level of Parkin in membrane. Parkin may induce the ubiquitination and degradation of membrane vATPase. Thus, DHA suppresses vATPase-mediated zymogen induced by cerulean. In summary, DHA inhibits zymogen activation, via GPR120 and GPR40, in pancreatic acinar AR42J cells stimulated with cerulein. Red arrows represent the effect of DHA. Black arrows mean the effect of cerulein stimulation

Sigma-Aldrich (St. Louis, MO, USA). A GPR40 antagonist DC260126 was purchased from Cayman Chemical (Ann Arbor, MI, USA). DHA was dissolved in $0.5 \mathrm{M}$ ethanol, while AH-7614, DC260126, and PYR-41 were dissolved in DMSO. Cerulein was dissolved in PBS containing $0.1 \%$ BSA, aliquoted, and stored at $-20{ }^{\circ} \mathrm{C}$.

\section{Cell culture}

Rat pancreatic acinar AR42J cells (pancreatoma, ATCC CRL 1492) were obtained from the American Type Culture Collection (Manassas, VA, USA) and cultured in Dulbecco's modified Eagle's medium (Sigma) supplemented with $10 \%$ fetal bovine serum (GIBCO-BRL, Grand Island, NY, USA) and antibiotics $(100 \mathrm{U} / \mathrm{mL}$ penicillin and $100 \mu \mathrm{g} / \mathrm{mL}$ streptomycin). Cells were cultured at $37{ }^{\circ} \mathrm{C}$ in a humidified atmosphere of $95 \%$ air and $5 \% \mathrm{CO}_{2}$.

\section{Experimental protocol}

Cells $\left(1 \times 10^{5} / \mathrm{mL}\right)$ were pretreated with DHA (20 or $50 \mu \mathrm{M})$, with or without AH-7614 $(10 \mu \mathrm{M})$, DC260126 $(10 \mu \mathrm{M})$, or PYR-41(20 or $50 \mu \mathrm{M})$ for $2 \mathrm{~h}$ and then stimulated with cerulein $\left(10^{-8} \mathrm{M}\right.$ ) for $30 \mathrm{~min}$ (for the determination of vATPase, GPR120, and GPR40 levels, and immunoprecipitation to assess the vATPase and ubiquitin interaction) or $2 \mathrm{~h}$ (for the determination of trypsin activity and amylase release). The concentrations of $\mathrm{AH}-$ 7614, DC260126, and PYR-41 and the culture periods used in the present study were adapted from previous studies [47-49].

\section{Preparation of cell extracts}

Cells were harvested using trypsin-EDTA and pelleted by centrifugation at $1000 \times g$ for $5 \mathrm{~min}$. Cell pellets were resuspended in lysis buffer containing $10 \mathrm{mM}$ Tris, $\mathrm{pH}$ 7.4; 1\% NonidetP-40 (NP-40); and a commercial protease inhibitor complex (Complete; Roche, Mannheim, Germany). Cells were lysed by drawing the cell suspension through a $1-\mathrm{mL}$ syringe with several rapid strokes. The mixture was then incubated on ice for $30 \mathrm{~min}$ and centrifuged at $13,000 \times g$ for $15 \mathrm{~min}$. Supernatants were collected and used as total cell extracts [50]. For subcellular fractionation, cell pellets were homogenized on ice with $300 \mu \mathrm{L}$ of homogenization buffer containing $0.3 \mathrm{M}$ sucrose, $10 \mathrm{mM}$ HEPES (pH 7.4), and a commercial protease inhibitor complex. They were then subjected to low-speed centrifugation $(500 \times g)$ for $10 \mathrm{~min}$ at $4{ }^{\circ} \mathrm{C}$ to remove nuclei and intact cells. The resulting postnuclear supernatants were subjected to high-speed centrifugation $(1,000,000 \times g)$ for $30 \mathrm{~min}$ at $4{ }^{\circ} \mathrm{C}$ in an Optima TLX Ultracentrifuge (Beckman Coulter Life Sciences, Indianapolis, IN, USA) to separate cytosolic and membrane fractions. The resulting supernatants were used as cytosolic extracts, and the pellets were resuspended in $70 \mu \mathrm{L}$ of homogenization buffer and used as membrane fractions. Protein concentrations were determined using the Bradford assay (Bio-Rad Laboratories, Hercules, CA, USA).

\section{Western blot analysis}

Whole-cell extracts $(5 \sim 30 \mu \mathrm{g})$ were separated by 8 $12 \%$ SDS-polyacrylamide gel electrophoresis, under reducing conditions and transferred onto nitrocellulose membranes (Amersham, Inc., Arlington Heights, IL, USA) by electroblotting. Protein transfer was verified using reversible staining with Ponceau S. Membranes were blocked with $3 \%$ non-fat dry milk in TBS-T (Tris-buffered saline and $0.2 \%$ Tween 20 ) for $1 \mathrm{~h}$ at room temperature. Proteins were detected using antibodies against vATPase E subunit (\#PA5-29899; Thermo Fisher Scientific, Rockford, IL, USA), GPR120 (H-155; sc-99105; Santa Cruz Biotechnology, Dallas, TX, USA), GPR40 (SAB4501280, Sigma-Aldrich), aldolase A (sc-12059, Santa Cruz Biotechnology), $\mathrm{Na}^{+} /$ $\mathrm{K}^{+}$-ATPase (sc-21712, Santa Cruz Biotechnology), and actin (sc-1615, Santa Cruz Biotechnology). Membranes were incubated overnight at $4{ }^{\circ} \mathrm{C}$ with primary antibodies diluted in TBS-T containing 3\% non-fat dry milk. After washing with TBS-T, primary antibodies were detected with horseradish peroxidaseconjugated secondary antibodies (anti-rabbit, antimouse, or anti-goat) and visualized using an enhanced chemiluminescence detection system (Santa Cruz Biotechnology) after exposure to BioMax MR film (Kodak, Rochester, NY, USA). The target protein 
levels were compared to the levels of the loading control, actin.

\section{Determination of trypsin activity and amylase release}

Trypsin activity was measured using a fluorogenic assay, with a substrate specific for trypsin (Boc-Glu-Ala-Arg-AMC; MQR-3135-v; Peptides International, Louisville, KY, USA). After the cells were treated with various agents, they were harvested using trypsin-EDTA and pelleted by centrifugation at $1000 \times g$ for $5 \mathrm{~min}$. Cell pellets were washed with ice-cold PBS and then resuspended in lysis buffer containing $50 \mathrm{mM}$ Tris, $\mathrm{pH} 8.0 ; 150 \mathrm{mM} \mathrm{NaCl} ; 1 \mathrm{mM} \mathrm{CaCl}$; and $0.1 \%$ BSA. Cells were then lysed by homogenization and drawing the cell suspension through a 1-mL syringe with several rapid strokes. The mixture was then centrifuged at $13,000 \times g$ for $10 \mathrm{~min}$. The substrate was added to the resulting supernatants to perform the assay. Trypsin activity was measured fluorometrically with excitation at $380 \mathrm{~nm}$ and emission at $440 \mathrm{~nm}$. Fluorescence was calibrated using a trypsin standard curve.

The amount of secreted amylase was determined in the media, while total amylase activity was determined in cells using an Amylase Activity Colorimetric Assay kit (K711-100; Biovision, Milpitas, CA, USA). For the determination of total intracellular amylase, acinar cells were homogenized in lysis buffer containing 50 $\mathrm{mM}$ Tris, $\mathrm{pH}$ 8.0. Amylase release was expressed as the percentage of secreted amylase/total amylase activity $[27,51]$.

\section{Immunoprecipitation analysis of the vATPase and ubiquitin Interaction}

Cells treated with or without DHA were lysed in $500 \mu \mathrm{M}$ of immunoprecipitation buffer containing $10 \mathrm{mM}$ Tris$\mathrm{HCl}, \mathrm{pH}$ 7.4; $100 \mathrm{mM} \mathrm{NaCl} ; 1 \mathrm{mM}$ EDTA; 1 mM EGTA; Complete protease inhibitors; $0.5 \%$ NP-40; $0.5 \%$ sodium deoxycholate; and $10 \%$ glycerol. Cells were then centrifuged at $15,000 \times g$ for $15 \mathrm{~min}$. A polyclonal antibody and protein G-agarose were added to the cleared supernatant, and the resulting mixture was incubated overnight at $4{ }^{\circ} \mathrm{C}$. The protein G-antibody-antigen complex was then collected by washing four times with immunoprecipitation buffer containing $150 \mathrm{mM} \mathrm{NaCl} ; 10 \mathrm{mM}$ Tris-HCl, pH 7.4; 1 mM EDTA; 1 mM EGTA; 0.5\% NP40; and $0.5 \%$ sodium deoxycholate. The final pellet was resuspended in $50 \mu \mathrm{L}$ of SDS sample buffer and boiled for $10 \mathrm{~min}$. This preparation was then subjected to western blot analysis. The level of the band densities corresponding to ubiquitinated vATPase E subunit to that of its input control was calculated. The band density level of "None" was set as $100 \%$. Values are expressed as the mean \pm S.E. of three/each group. A $p$ value of 0.05 or less was considered statistically significant.

\section{Statistical analysis}

All values were expressed as the mean \pm S.E. of three independent experiments. Analysis of variance (ANOVA), followed by Newman-Keul's post hoc test was used for statistical analysis. A $p$ value $\leq 0.05$ was considered statistically significant.

\section{Abbreviations \\ CCK: Cholecystokinin; DHA: Docosahexaenoic acid; GPR: G-protein coupled receptor; PUFA: Polyunsaturated fatty acid; vATPase: Vacuolar ATPase}

\section{Acknowledgements}

Not applicable.

\section{Authors' contributions}

YP and LK performed the research. YP wrote the paper. JWL contributed new reagents and analytical tools. HK designed the research, analyzed the data, and edited the paper. All authors approved the manuscript in its current form.

\section{Funding}

This study was supported by a Brain Korea 21 Plus Project, Yonsei University, Seoul 03722, The Republic of Korea.

\section{Availability of data and materials}

All data generated or analyzed during this study are included in this published article.

Ethics approval and consent to participate

Not applicable.

Consent for publication

Not applicable.

\section{Competing interests}

The authors declare that they have no competing interests.

Received: 12 August 2019 Accepted: 5 March 2020

Published online: 23 March 2020

\section{References}

1. Leach SD, Modlin IM, Scheele GA, Gorelick FS. 1991 Intracellular activation of digestive zymogens in rat pancreatic acini. Stimulation by high doses of cholecystokinin. J Clin Invest. 1991;87:362-6.

2. Bhatia M, Wong FL, Cao Y, Lau HY, Huang J, Puneet P. Chevali L. Pathophysiology of acute pancreatitis Pancreatology. 2005;5:132-44.

3. Saluja AK, Michael LS. Pathophysiology of pancreatitis Role of cytokines and other mediators of inflammation. Digestion. 1999;60:27-33.

4. Jean-Louis F, Hadengue A, Pastor CM. New serum markers for the detection of severe acute pancreatitis in humans. Am J Respir Crit Care Med. 2001;164: 162-70.

5. Hofbauer B, Saluja AK, Lerch MM. Bhagat L, Bhatia M, Lee HS, Frossard JL, Adler G, Steer ML. Intra-acinar cell activation of trypsinogen during caerulein-induced pancreatitis in rats. Am J Physiol. 1998;275:G352-G362.

6. Lerch MM, Adler G. Experimental animal models of acute pancreatitis. Int J Pancreatol. 1994;15:159-70.

7. Jensen RT, Wank SA, Rowley WH, Sato S, Gardner JD. Interaction of CCK with pancreatic acinar cells. Trends Pharmacol Sci. 1989:10:418-23.

8. Sato S, Stark HA, Martinez J, Sato S, Gardner JD. Receptor occupation calcium mobilization and amylase release in pancreatic acini: effect of CCKJMV-180. Am J Physiol. 1989;257:G202-9.

9. Kim H. Cerulein pancreatitis: oxidative stress inflammation and apoptosis. Gut Liver. 2008;2:74-80.

10. Willemer S, Elsässer HP, Adler G. Hormone-induced pancreatitis. Eur Surg Res. 1992;24 Suppl1:29-39.

11. Heinrich S, Schäfer M, Rousson V, Clavien PA. Evidence-based treatment of acute pancreatitis: a look at established paradigms. Ann Surg. 2006; 243:154-68

12. Gorelick FS, Thrower E. The acinar cell and early pancreatitis responses. Clin Gastroenterol Hepatol. 2009;7:S10-4. 
13. Schoenberg MH, Büchler M, Gaspar M, Stinner A, Younes M, Melzner I, Bültmann B, Beger HG. Oxygen free radicals in acute pancreatitis of the rat Gut. 1990;31:1138-43.

14. Nelson N, Perzov N, Cohen A, Hagai K, Padler V, Nelson H. The cellular biology of proton-motive force generation by V-ATPases. J Exp Biol. 2000;203:89-95.

15. Ohira M, Smardon AM, Charsky CM, Liu J, Tarsio M, Kane PM. The E and G subunits of the yeast V-ATPase interact tightly and are both present at more than one copy per V1 complex. J Biol Chem. 2006;28:22752-60.

16. Waterford SD, Kolodecik TR, Thrower EC, Thrower EC, Gorelick FS. Vacuolar ATPase regulates zymogen activation in pancreatic acini. J Biol Chem. 2005; 280:5430-4

17. Chung C, Mader CC, Schmitz J, Atladottir J, Fitchev P, Cornwell ML, Koleske AJ, Crawford SE, Gorelick F. The vacuolar-ATPase modulates matrix metalloproteinase (MMP) isoforms in human pancreatic cancer. Lab Invest. 2011;91:732-43.

18. Shugrue CA, Alexandre M, Diaz de Villalvilla A, Kolodecik TR, Young LH, Gorelick FS, Thrower EC. Cerulein hyperstimulation decreases AMP-activated protein kinase levels at the site of maximal zymogen activation. Am J Physiol Gastrointest Liver Physiol. 2012;303:G723-32.

19. Martinez A, Lectez B, Ramirez J, Popp O, Sutherland JD, Urbé S, Dittmar G, Clague MJ, Mayor U. Quantitative proteomic analysis of Parkin substrates in Drosophila neurons. Mol Neurodegener. 2017;12:29.

20. Moyad MA. An introduction to dietary/supplemental omega-3 fatty acids for general health and prevention: part II. Urol Oncol. 2005;23:36-48.

21. Oh DY, Talukdar S, Bae EJ, Imamura T, Morinaga H, Fan W, Li P, Lu WJ, Watkins SM, Olefsky JM. GPR120 is an omega-3 fatty acid receptor mediating potent anti-inflammatory and insulin-sensitizing effects Cell. 2010;142:687-98

22. Sona C, Kumar A, Dogra S, Kumar BA, Umrao D, Yadav PN. Docosahexaenoic acid modulates brain-derived neurotrophic factor via GPR40 in the brain and alleviates diabesity-associated learning and memory deficits in mice. Neurobiol Dis. 2018;118:94-107.

23. Kim N, Lee JO, Lee HJ, Kim HI, Kim JK, Lee YW, Lee SK, Kim SJ, Park SH, Kim HS. Endogenous ligand for GPR120 docosahexaenoic acid exerts benign metabolic effects on the skeletal muscles via AMP-activated protein kinase pathway. J Biol Chem. 2015;290:20438-47.

24. Nakamoto K, Nishinaka T, Sato N, Mankura M, Koyama Y, Kasuya F, Tokuyama S. Hypothalamic GPR40 signaling activated by free long chain fatty acids suppresses CFA-induced inflammatory chronic pain. PLoS One. 2013;8:e81563

25. Calviello G, Resci F, Serini S, Piccioni E, Toesca A, Boninsegna A, Monego G, Ranelletti FO, Palozza P. Docosahexaenoic acid induces proteasomedependent degradation of $\beta$-catenin down-regulation of survivin and apoptosis in human colorectal cancer cells not expressing COX-2. Carcinogenesis. 2006;28:1202-9.

26. Jing K, Shin S, Jeong S, Kim S, Song KS, Park JH, Heo JY, Seo KS, Park SK, Kweon GR, Wu T, Park Jl, Lim K. Docosahexaenoic acid induces the degradation of HPV E6/E7 oncoproteins by activating the ubiquitinproteasome system. Cell Death Dis. 2014;5e1524.

27. Frossard JL, Bhagat L, Lee HS, Hietaranta AJ, Singh VP, Song AM, Steer ML, Saluja AK. Both thermal and non-thermal stress protect against caerulein induced pancreatitis and prevent trypsinogen activation in the pancreas. Gut. 2002:50:78-83.

28. Cosen-Binker LI, Gaisano HY, Herbert Y. Recent insights into the cellular mechanisms of acute pancreatitis. Can J Gastroenterol. 2007:21:19-24.

29. Krüger $B$, Albrecht $E$, Lerch MM. The role of intracellular calcium signaling in premature protease activation and the onset of pancreatitis. Am J Pathol. 2000;157:43-50

30. Kim YJ, Chung HY. Antioxidative and anti-inflammatory actions of docosahexaenoic acid and eicosapentaenoic acid in renal epithelial cells and macrophages. J Med Food. 2007;10:225-31.

31. Lei QC, Wang XY, Xia XF, Zheng HZ, Bi JC, Tian F, Li N. The role of omega-3 fatty acids in acute pancreatitis: a meta-analysis of randomized controlled trials. Nutrients. 2015;7:2261-73.

32. Jeong YK, Lee S, Lim JW, Kim H. Docosahexaenoic acid inhibits ceruleininduced acute pancreatitis in rats. Nutrients. 2017:9:E744.

33. Park KS, Lim JW, Kim H. Inhibitory mechanism of omega-3 fatty acids in pancreatic inflammation and apoptosis. Ann N Y Acad Sci. 2009;1171:421-7.

34. Song EA, Lim JW, Kim H. Docosahexaenoic acid inhibits IL-6 expression via PPARy-mediated expression of catalase in cerulein-stimulated pancreatic acinar cells. Int J Biochem Cell Biol. 2017;88:60-8.
35. Niederau C, Grendell JH. Intracellular vacuoles in experimental acute pancreatitis in rats and mice are an acidified compartment. J Clin Invest. 198:881:229-36.

36. Leach SD, Bilchik AJ, Karapetian O, Gorelick FS, Modlin IM. Influence of chloroquine on diet-induced pancreatitis. Pancreas. 1993;8:64-9.

37. Panicker N, Dawson VL, Dawson TM. Activation mechanisms of the E3 ubiquitin ligase parkin. Bochem J. 2017:474:3075-86.

38. Corsa CAS, Pearson GL, Renberg A, Askar MM, Vozheiko T, MacDougald OA, Soleimanpour SA. The E3 ubiquitin ligase parkin is dispensable for metabolic homeostasis in murine pancreatic $\beta$ cells and adipocytes. J Bio Chem. 2019:294:7296-307.

39. Shimura H, Hattori N, Kubo Si, Mizuno Y, Asakawa S, Minoshima S, Shimizu N, Iwai K, Chiba T, Tanaka K, Suzuki T. Familial Parkinson disease gene product, parkin, is an ubiquitin-protein ligase. Nat Genet. 2000;25:302-305.

40. Zhang Y, Gao J, Chung KK, Huang H, Dawson VL, Dawson TM. Parkin functions as an E2-dependent ubiquitin- protein ligase and promotes the degradation of the synaptic vesicle-associated protein, CDCrel-1. Proc Natl Acad Sci U S A. 2000;97:13354-9.

41. Piplani H, Marek-lannucci S, Sin J, Hou J, Takahashi T, Sharma A, de Freitas GJ, Waldron RT, Saadaeijahromi H, Song Y, Gulla A, Wu B, Lugea A, Andres AM, Gaisano HY, Gottlieb RA, Pandol SJ. Simvastatin induces autophagic flux to restore cerulein-impaired phagosome-lysosome fusion in acute pancreatitis. Biochim Biophys Acta Mol Basis Dis. 2019;1865:165530.

42. Lu Z, Kolodecik TR, Karne S, Nyce M, Gorelick F. Effect of ligands that increase CAMP on caerulein-induced zymogen activation in pancreatic acini. Am J Physiol Gastrointest Liver Physiol. 2003:285:G822-8.

43. Jonas L, Mikkat U, Witte A, Beckmann U, Dölker K, Weber H, Hahnel C, Kundt G, Nizze H. Morphometric measurements to quantify the cerulein induced hyperstimulatory pancreatitis of rats under the protective effect of lectins. Anal Cell Pathol. 1998;17:219-30.

44. Le Petit-Thévenin J, Bruneau N, Nganga A, Lombardo D, Vérine A. Effects of arachidonic and docosahexaenoic acids on secretion and degradation of bile salt-dependent lipase in AR4-2J cells. J Lipid Res. 2001:42:1220-30.

45. Chen C, Meng Y, Wang L, Wang H-X, Tian C, Pang G-D, Li H-H, Jie D. Ubiquitin-activating enzyme E1 inhibitor PYR41 attenuates angiotensin IIinduced activation of dendritic cells via the $\mathrm{KKBa} / \mathrm{NF}-\mathrm{KB}$ and MKP1/ERK STAT1 pathways. Immunology. 2014:142:307-19.

46. Pesiri $V$, Totta $P$, Marino M, Acconcia F. Ubiquitin-activating enzyme is necessary for 17ß-estradiol-induced breast cancer cell proliferation and migration. IUBMB Life. 2014;66:578-85.

47. Villegas-Comonfort S, Takei Y, Tsujimoto G, Tsujimoto G, Hirasawa A, GarcíaSáinz JA. Effects of arachidonic acid on FFA4 receptor: signaling phosphorylation and internalization. Prostaglandins Leukot Essent Fatty Acids. 2017;117:1-10.

48. Kristinsson H, Bergsten P, Sargsyan E. Free fatty acid receptor 1 (FFAR1/ GPR40) signaling affects insulin secretion by enhancing mitochondrial respiration during palmitate exposure. Biochim Biophys Acta. 1853;2015: 3248-57.

49. Hartz AM, Zhong Y, Wolf A, LeVine $H 3^{\text {rd }}$, Miller DS, Bauer B. A 440 reduces P-glycoprotein at the blood-brain barrier through the ubiquitinproteasome pathway. J Neurosci. 2016;36:1930-1941.

50. Park M, Lim JW, Kim H. Docoxahexaenoic acid induces apoptosis of pancreatic cancer cells by suppressing activation of STAT3 and NF-KB. Nutrients. 2018;10:E1621.

51. Lupia E, Goffi A, De Giuli P, Azzolino O, Bosco O, Patrucco E, Vivaldo MC, Ricca M, Wymann MP, Hirsch E, Montrucchio G, Emanuelli G. Ablation of phosphoinositide 3-kinase-gamma reduces the severity of acute pancreatitis. Am J Pathol. 2004;165:2003-11.

\section{Publisher's Note}

Springer Nature remains neutral with regard to jurisdictional claims in published maps and institutional affiliations. 